States of America; ${ }^{2}$ Mayo Clinic, Health Sciences Research, Rochester, United States of America

Background: Several studies show increased risk of dementia among individuals with rheumatoid arthritis (RA), while others show no association. One reason for this discrepancy might be differential association by serostatus. No prior studies have investigated the association between RA and dementia by serostatus. Objectives: We aimed to evaluate the risk of incident dementia among individuals with RA, stratified by serostatus.

Methods: This population-based cohort study included all cases of incident RA within Olmsted County, Minnesota with index date of RA onset between 1 January 1999 and 31 December 2013. We matched RA cases to non-RA comparators $1: 1$ on age and sex. All RA cases met 1987 ACR criteria for RA. We defined seropositivity as positive rheumatoid factor or anti-cyclic citrullinated peptide antibodies. We defined incident dementia as having two ICD-9/10 codes for dementia at least 30 days apart, with the date of the second code representing the time of dementia onset. We excluded individuals with dementia prior to index date. We estimated the cumulative incidence of dementia adjusting for the competing risk of death. For the main analysis, cox proportional hazard models estimated adjusted hazard ratios (aHR) with 95\% confidence intervals $(\mathrm{Cl})$ for incident dementia, adjusting for age, sex, index year, body mass index, and smoking status (never, former, current). These models compared the incidence of dementia for RA versus non-RA, seropositive and seronegative RA versus their matches, and seropositive versus seronegative RA. To validate these results, we also performed sensitivity analyses using groups matched via inverse probability weighting on age, sex, index year, obesity, smoking status, and race.

Results: We identified 597 RA cases (mean age 56, 70\% female), and 594 non-RA comparators. Of the RA cases, 388 (65\%) were seropositive, and 209 $(35 \%)$ were seronegative. The ten-year cumulative incidence of dementia in patients with RA was $3.3(95 \% \mathrm{Cl} 2.0,5.5)$ per 100,000 compared to $2.4(95 \% \mathrm{Cl}$ $1.3,4.2)$ in non-RA comparators, for aHR of $1.26(95 \% \mathrm{Cl} 0.7,2.3)$. When stratifying by serostatus, the ten-year incidence of dementia for seropositive RA cases was $3.6(95 \% \mathrm{Cl} 2.0,6.5)$, corresponding to aHR of $1.45(95 \% \mathrm{Cl} 0.73,2.9)$ compared to matched non-RA cases. In contrast, the incidence of dementia in seronegative RA cases was $2.6(95 \% \mathrm{Cl} 1.0,7.0)$, for an aHR of $1.0(95 \% \mathrm{Cl} 0.29,3.5)$. Overall, the incidence of dementia in seropositive RA cases was significantly higher than seronegative cases (aHR 3.2, 95\% Cl 1.2,8.5). Indeed, sensitivity analysis using inverse probability weighting confirmed that among participants aged 50 and older, dementia incidence was higher for seropositive than seronegative RA (aHR 2.9, 95\%Cl1.1,7.8) (Figure 1).

Conclusion: Individuals with seropositive RA have an increased risk for incident dementia than those with seronegative RA. Future studies should replicate these findings and investigate the mechanism for this association.

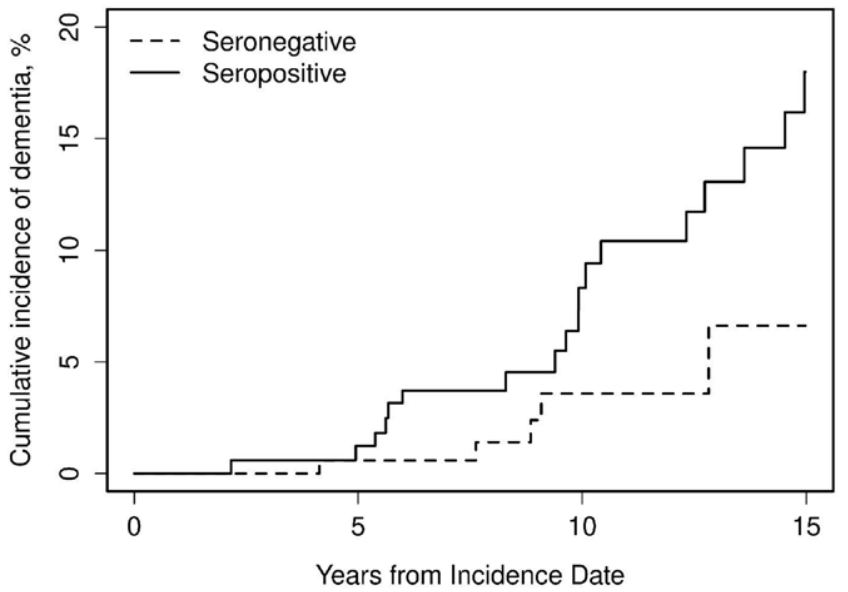

Figure 1. Cumulative incidence of dementia for individuals with seropositive versus seronegative $\mathrm{RA}$ aged 50 and older, balanced by inverse probability weighting

Acknowledgements: This work was funded by grants from the National Institutes of Health, NIAMS (R01 AR46849) and NIA (R01 AG068192, R01 AG034676).

Disclosure of Interests: Vanessa Kronzer: None declared, Tina Gunderson: None declared, Cynthia S. Crowson: None declared, John M Davis III Grant/ research support from: Pfizer, Maria Vassilaki Shareholder of: equity ownership in Abbott Laboratories, Johnson and Johnson, Medronic and Amgen; Grant/research support from: Roche and Biogen, Michelle Mielke Consultant of: Biogen and Brain Protection Company, Elena Myasoedova: None declared

DOI: 10.1136/annrheumdis-2021-eular.2172

\section{POS0310 EXPOSURE TO MAJOR PSYCHOLOGICAL TRAUMA OR STRESS INTHE PRECEDING ONE YEAR SIGNIFICANTLY CONTRIBUTES TO POOR DISEASE CONTROL IN PATIENTS WITH RHEUMATOID ARTHRITIS: SINGLE CENTRE RESULTS FROM THE PRIME REGISTRY COHORT}

M. Haroon ${ }^{1}$, S. Asif ${ }^{1}$, S. Batool ${ }^{1}$, F. Hashmi' ${ }^{1}$ S. Ullah ${ }^{1}$, A. Ashraf ${ }^{2}$, H. J. Shaheen ${ }^{1} .{ }^{1}$ Fatima Memorial Hospital \& FMH College of Medicine and Dentistry, Department of Rheumatology, Lahore, Pakistan; ${ }^{2} \mathrm{CMH}$ Lahore Medical College \& Institute of Dentistry, Medicine, Lahore, Pakistan

Background: Stress response is considered to involve the activation of both the hypothalamus-pituitary-adrenal axis and the autonomic nervous system, along with its communication with the immune system. Because many rheumatic diseases are characterized by immune-mediated joint inflammation, stressful events might contribute to the aetiology, maintenance and exacerbation of rheumatic diseases.

Objectives: We aimed to examine whether real-life major stressful events lead to poor disease control among patients with Rheumatoid arthritis (RA). We addressed this question using real-world data from the PRIME registry.

Methods: This was a cross-sectional study conducted using data collected at the time of patient enrolment in the PRIME registry. The PRIME Registry is a large, independent, prospective, observational cohort initiated in October 2019 that comprises patients diagnosed with RA, SLE, PsA or AS by a rheumatologist, and is being actively followed up. IRB approval and informed consent was obtained. We assessed the registry data for RA patients. The clinical variables studied were gender, age, smoking habits, body mass index, education status, marital status, disease duration, comorbidities (using Charlson Comorbidity Index). Education status was stratified by whether participants completed secondary (high) school education. Evaluation of disease activity and severity was made as per internationally agreed definitions, such as: swollen joint counts (SJC), tender joint counts (TJC), deformed joint counts, and DAS-28. Major psychological trauma or stress was defined if the patient has experienced any of the following in the past year: a) major personal injury or illness; b) death/major illness of a close relative; c) marital separation/divorce; d) loss of job; e) major financial loss; f) mass casualty incident loss.

Results: The data of consecutive 507 RA patients (mean age $42.3 \pm 12.6$ years, $73.6 \%$ female, disease duration of $80 \pm 22$ months) was reviewed. Thirty-six percent of the cohort reported to have major psychological stress and trauma in the preceding one year. No statistical association of age, gender, and marital status was noted, but statistical association of low education status $(p=0.042)$, longer disease duration $(p=0.044)$, higher DAS-28 values $(p<0.001)$ and other markers of RA disease activity (SJC, TJC, ESR, patient global health) was found. On multiple logistic regression analysis, a significant association of major psychological stress and trauma in the preceding one year was noted with active disease (DAS-28; OR 1.67, $\mathrm{Cl} 1.17-2.4, \mathrm{p}=0.005)$. Following variables were included in the full regression model, disease duration, gender, age, marital status, education status, and DAS-28 value (also used models with SJC, TJC, deformed joint counts, ESR, patient global health, but the results remained unchanged).

Conclusion: Major psychological stress and trauma in the preceding one year is associated with high disease activity among patients with RA. Therapies that focus on stress management may be important adjuncts to traditional pharmacotherapy in the treatment of inflammatory rheumatic diseases.

Disclosure of Interests: Muhammad Haroon Speakers bureau: Roche, Novartis, Grant/research support from: Abbvie, Pfizer, Sadia Asif: None declared, Shabnam Batool: None declared, Farzana Hashmi: None declared, Saadat Ullah: None declared, Arfa Ashraf: None declared, Hafiza Javeria Shaheen: None declared

DOI: 10.1136/annrheumdis-2021-eular.2101

POS0311

NEUROIMAGING BIOMARKERS IN INDIVIDUALS WITH AND WITHOUT RHEUMATOID ARTHRITIS: RESULTS FROM THE MAYO CLINIC STUDY OF AGING

M. Vassilaki ${ }^{1}$, C. S. Crowson ${ }^{1}$, J. M. Davis $\mathrm{II}^{2}$, S. Duong ${ }^{1}$, D. Jones ${ }^{3}$ M. Mielke ${ }^{1,4}$, P. Vemuri ${ }^{3}$, E. Myasoedova ${ }^{1,2}{ }^{1}$ Mayo Clinic, Department of Quantitative Health Sciences, Rochester, United States of America; ${ }^{2}$ Mayo Clinic, Division of Rheumatology, Rochester, United States of America; ${ }^{3}$ Mayo Clinic, Department of Radiology, Rochester, United States of America; ${ }^{4}$ Mayo Clinic, Department of Neurology, Rochester, United States of America

Background: Age-related increase in the burden of systemic inflammation is an established key player and potential treatment target in Alzheimer's disease (AD) and other age-related dementias. (Dregan, Chowienczyk et al. 2015) Although rheumatoid arthritis (RA) is an autoimmune hyper-inflammatory disease, studies on RA and dementia or vascular neuroimaging biomarkers are lacking.

Objectives: To examine the associations between RA and dementia/vascular neuroimaging biomarkers in the Mayo Clinic Study of Aging (MCSA). 
Methods: The study consisted of 35 RA cases in MCSA and 104 MCSA participants without RA matched 1:3 for age, sex, education, cognitive status ( $\geq 50$ years old) at baseline and the availability of at least one magnetic resonance imaging (MRI). The primary outcome measures were well established dementia-related neuroimaging biomarkers, including global beta-amyloid $(A \beta)$ using PiB-positron-emission tomography (PET; $n=47$ ); neurodegeneration (hypometabolism via FDG-PET $(n=45)$, hippocampal volume $(n=139)$, and cortical thickness via structural MRI $[n=138]$, and cerebrovascular pathology via FLAIRMRI (white matter hyperintensity [WMH; $n=49$ ] burden, subcortical, and cortical infarctions $(n=55)$ ). Elevated ${ }^{11} \mathrm{C}$-PiB-PET was defined as standardized uptake value ratio $\geq 1.48$ in an Alzheimer's disease (AD)-related region of interest and reduced $A D$ signature cortical thickness as $\leq 2.68 \mathrm{~mm}$ (neurodegeneration; $\mathrm{N}+$ ). Kruskal-Wallis rank sum and Pearson's chi-squared tests were used to compare the neuroimaging measures between participants with and without RA.

Results: Participants with vs. without-RA did not differ in age, sex, years of education, major comorbidities, $A \beta$ burden, hippocampal volume, and neurodegeneration measures (Table 1). Although the sample size was small, we observed that RA participants (vs. without-RA) had greater mean WMH volume (relative to the total intracranial volume (TIV) (mean (SD) \%: $1.12(0.57) \%$ vs $0.76(0.69)$ $\%$ of TIV, $p=0.011$ ), were more likely to have cortical infarctions ( $4 \mathrm{vs.1} ; p=0.013$ ) and had a higher mean number of cortical infarctions (mean (SD): $0.24(0.44)$ vs. 0.05 (0.32), $p=0.017)$.

Conclusion: Our preliminary data suggest significant differences in cerebrovascular biomarker measures by RA status. Further studies would add valuable information to our understanding and insight into the development of interventions for the prevention of cerebrovascular pathology in RA patients.

REFERENCES:

[1] Dregan, A., P. Chowienczyk and M. C. Gulliford (2015). "Are Inflammation and Related Therapy Associated with All-Cause Dementia in a Primary Care Population?" J Alzheimers Dis 46(4): 1039-1047.

Table 1. Participants' baseline characteristics.

\begin{tabular}{lcccc}
\hline & With RA & Without RA & Total & p value* \\
\hline Age, mean (SD) & $76.3(7.9)$ & $75.9(7.9)$ & 139 & 0.82 \\
Male & $13(37 \%)$ & $37(36 \%)$ & 139 & 0.87 \\
Education (years), mean (SD) & $14.5(2.5)$ & $14.3(2.4)$ & 139 & 0.75 \\
Apolipoprotein E 4 carrier & $6(17 \%)$ & $28(27 \%)$ & 139 & 0.24 \\
Cognitively unimpaired & $27(77 \%)$ & $83(80 \%)$ & 110 & 0.94 \\
Mild cognitive impairment & $7(20 \%)$ & $18(17 \%)$ & 25 & \\
Dementia & $1(3 \%)$ & $3(3 \%)$ & 4 & \\
Reduced AD signature cortical thickness & $20(57 \%)$ & $60(58 \%)$ & 138 & 0.91 \\
Elevated $\beta$-amyloid & $4(33 \%)$ & $11(31 \%)$ & 47 & 0.90 \\
FDG PET SUVR & $1.52(0.16)$ & $1.59(0.18)$ & 45 & 0.46 \\
White matter hyperintensity volume \% of TIV & $1.12(0.57)$ & $0.76(0.69)$ & 49 & 0.011 \\
With cortical infarctions & $4(24 \%)$ & $1(3 \%)$ & 55 & 0.013
\end{tabular}

$\mathrm{N}(\%)$ unless otherwise stated; * Kruskal-Wallis rank sum or Pearson's Chi-squared test.SD=standard deviation; $A D=$ Alzheimer's disease; $S U V R=$ standardized uptake value ratio; TIV= Total intracranial volume.

Acknowledgements: The study was supported by the NIH AG068192. The Mayo Clinic Study of Aging was supported by the NIH (U01 AG006786, P50 AG016574, R01AG057708, R01 AG011378, R01 AG021927, R01 AG041851, R01 NS097495), the Alexander Family Alzheimer's Disease Research Professorship of the Mayo Clinic, Mayo Foundation for Medical Education and Research, the Liston Award, the Schuler Foundation and was made possible by the Rochester Epidemiology Project (R01 AG034676).

Disclosure of Interests: Maria Vassilaki Shareholder of: M. Vassilaki has equity ownership in Abbott Laboratories, Johnson and Johnson, Medronic and Amgen. Grant/research support from: M. Vassilaki has received research funding from Roche and Biogen in the past., Cynthia S. Crowson: None declared, John M Davis III Grant/research support from: JM. Davis III receives research funding from Pfizer., Stephanie Duong: None declared, David Jones: None declared, Michelle Mielke Consultant of: M. Mielke has consulted for Biogen and Brain Protection Company, Prashanthi Vemuri: None declared, Elena Myasoedova: None declared

DOI: 10.1136/annrheumdis-2021-eular.1137

\section{POS0312 HOW DOES THE PRESENCE OF DEPRESSION IMPACT ON DISEASE ACTIVITY SCORES IN PATIENTS WITH RHEUMATOID ARTHRITIS?}

C. A. Isnardi ${ }^{1}$, E. E. Schneeberger ${ }^{1}$, D. Capelusnik ${ }^{1}$, M. Bazzarelli ${ }^{2}$, L. Barloco ${ }^{3}$, E. S. Blanco ${ }^{4}$, A. Benitez ${ }^{4}$, F. Benavidez ${ }^{4}$, S. Scarafia ${ }^{5}$, M. A. Lazaro ${ }^{5}$, R. Perez Alamino $^{6}$, F. Colombres ${ }^{6}$, M. P. Kohan ${ }^{7}$, J. Sosa ${ }^{7}$, L. Gonzalez Lucero ${ }^{8}$, A. L. Barbaglia ${ }^{8}$, H. Maldonado Ficco ${ }^{9}$, G. Citera ${ }^{1} .{ }^{1}$ Psychophysical Rehabilitation Institute, Rheumatology, DQG, Argentina; ${ }^{2}$ Hospital Provincial Petrona V. de Cordero, Rheumatology, San Fernando, Argentina; ${ }^{3}$ Hospital Provincial Petrona V. de Cordero, Terapia ocupacional, San Fernando, Argentina; ${ }^{4}$ General Hospital
Dr. Cosme Argerich Treble, Rheumatology, AHD, Argentina; ${ }^{5}$ IARI-Instituto de Asistencia Reumatológica Integral, Rheumatology, San Fernando, Argentina; ${ }^{6}$ Hospital de Clínicas Nicolás Avellaneda, Rheumatology, San Miguel de Tucumán, Argentina; ${ }^{7}$ Dr. Enrique Tornú Hospital, Rheumatology, Ciudad de Buenos Aires, Argentina; ${ }^{8}$ Hospital Ángel C. Padilla, Rheumatology, San Miguel de Tucumán, Argentina; ${ }^{9}$ Nuevo Hospital Río Cuarto "San Antonio de Padua", Rheumatology, Río Cuarto, Argentina

Background: Depression is present in up to half of patients with Rheumatoid Arthritis (RA). The association between this mood disorder and disease activity scores, including DAS28, SDAI and CDAI, has previously been described by various authors. Objectives: The aim of our study was assessed the effect of depression on the components of different disease activity scores.

Methods: We performed a cross-sectional study of consecutive adults with RA, according to ACR/EULAR 2010 criteria. Sociodemographic data, comorbidities and current treatment were recorded. Disease activity was evaluated using DAS28-ESR, DAS28-CRP, SDAI and CDAI. Depression was assessed using PHQ-9 questionnaire. The PHQ-9 values were categorized in 4 groups as follows: 5 to 9,10 to 14,15 to 19,20 or greater, represents mild, moderate, moderate/severe, and severe depression, respectively. A cutoff value of 10 or greater was set to define major depression. Statistical analysis: Student's T, ANOVA and $\mathrm{Chi}^{2}$ tests. Multiple logistic regression.

Results: Two hundred fifty eight patients were included, with a median $(m)$ disease duration of 9 years (IQR 3.6-16.7). The $m$ PHQ-9 score was 6 (IQR 2-12.3) and the prevalence of major depression was $33.7 \%$. Patients with major depression had more tender and swollen joint count (TJC and SJC) (mean $4.9 \pm 4.3 \mathrm{vs}$ $2.3 \pm 3.7, p<0.0001$ and $2.9 \pm 3.3$ vs $1.7 \pm 3.4, p=0.009$ ), more pain $(V A S[\mathrm{~cm}]$ mean $5.6 \pm 2.7$ vs $3.3 \pm 2.6, p<0.0001$ ), higher patient and physician global assessment (PGA and PhGA) (VAS [cm] mean $5.4 \pm 2.9$ vs $3.1 \pm 2.5, p<0.0001$ and $4.4 \pm 2.7$ vs $2.4 \pm 2.4, p<0.0001$ ) and CRP (mean $1.7 \pm 3.3$ vs $0.7 \pm 1.1 \mathrm{mg} / \mathrm{dl}, \mathrm{p}=0.01$ ). ESR values were higher in the group with major depression, but the difference did not reach significance. Disease activity was higher in the depression group by all scores: DAS28-ESR (mean $4.3 \pm 1.4$ vs $3.3 \pm 1.3, p<0.0001$ ), DAS28-CRP (mean $3.9 \pm 1.4$ vs $2.8 \pm 1.7, p<0.0001$ ), SDAl (mean $19.2 \pm 12.7$ vs $10.3 \pm 10.1, p<0.0001$ ) and CDAl (mean $17.6 \pm 10.9$ vs $9.6 \pm 9.9, p<0.0001)$. While $41(15.9 \%)$ patients had high disease activity according to DAS28-ESR, only 34 (13.2\%) had SDAI>26. In the multivariate analysis, evaluating the association of major depression with the different components of DAS28-ESR, DAS28-CRP, SDAI and CDAI, we observed that the presence of this mood disorder remained significantly associated with higher PGA in all the scores. In addition, a significant association was seen with higher TJC in both DAS28 scores.

Conclusion: Patients with major depression had higher disease activity. It's presence has a significantly association with the subjective items of the disease activity scores, particularly PGA. CRP value was the only objective component associated with depression

Disclosure of Interests: Carolina Ayelen Isnardi Speakers bureau: Bristol Myers Squibb, Janssen, Grant/research support from: Pfizer, Emilce Edith Schneeberger Speakers bureau:Abbvie, Amgen, Bristol Myers Squibb, Janssen, Eli Lilly, Boehringer Ingelheim, Pfizer, Genzyme, Grant/research support from: Pfizer, Dafne Capelusnik Speakers bureau: Bristol Myers Squibb, Grant/research support from: Pfizer, Marcela Bazzarelli: None declared, Laura Barloco: None declared, Eliana Soledad Blanco: None declared, Alejandro Benitez Speakers bureau: Abbvie, Novartis, Amgen, Federico Benavidez: None declared, SANTIAGO SCARAFIA: None declared, María Alicia Lazaro Speakers bureau: Abbvie, Rodolfo Perez Alamino Speakers bureau: Pfizer, Abbvie, Amgen, Bristol-Myers-Squibb, Lilly, Janssen, Novartis, Federico Colombres: None declared, María Paula Kohan: None declared, Julia Sosa: None declared, Luciana Gonzalez Lucero: None declared, Ana Lucía Barbaglia: None declared, Hernan Maldonado Ficco Speakers bureau: Pfizer, Abbvie, Jansen, Novartis, Bago, Bristol, Eli Lilly., Consultant of: Pfizer, Abbvie, Novartis, Jansen, Bago, Eli Lilly., Gustavo Citera Speakers bureau: Abbvie, Bristol-Myers-Squibb, Lilly, Jansen, Gema, Pfizer, Roche, Grant/research support from: Pfizer DOI: 10.1136/annrheumdis-2021-eular.1374

\section{POS0313 INCIDENCE AND PREVALENCE OF POLYAUTOIMMUNITY IN SEROPOSITIVE COMPARED WITH SERONEGATIVE PATIENTS WITH RHEUMATOID ARTHRITIS: A NATIONWIDE COHORT STUDY}

A. Hagelskjær ${ }^{1}$, R. Cordtz ${ }^{1}$, S. Bliddal ${ }^{2}$, A. S. Mortensen ${ }^{1}$, S. Kristensen ${ }^{1,3}$ C. H. Nielsen ${ }^{4}$, U. Feldt-Rasmussen ${ }^{2,5}$, C. Torp-Pedersen ${ }^{6}$, L. Dreyer ${ }^{1,3,7}$. ${ }^{1}$ Aalborg University Hospital, Department of Rheumatology, Aalborg, Denmark; ${ }^{2}$ Copenhagen University Hospital, Rigshospitalet, Department of Medical Endocrinology and Metabolism, København, Denmark; ${ }^{3}$ Aalborg University, Department of Clinical Medicine, Aalborg, Denmark; ${ }^{4}$ Copenhagen University Hospital, Rigshospitalet, Institute of Inflammation Research, København, Denmark; ${ }^{5}$ University of Copenhagen, Department of Clinical Medicine, Copenhagen, Denmark; ${ }^{6}$ North Zealand Hospital - Hillerød, Department of Cardiology, Hillerød, Denmark; ${ }^{7}$ DANBIO, Denmark, Nationwide, Denmark 